\title{
Clinical Evaluation of Locally Made Flocked Swabs in Response to the COVID- 19 Pandemic in a Developing Country
}

\author{
Narottama Tunjung1, Prasetyanugraheni Kreshanti1,2*, Yulia Rosa Saharman ${ }^{3}$, Yudan \\ Whulanza $^{2,4}$, Sugeng Supriadi ${ }^{2,5}$, Mochammad Chalid ${ }^{4}$, Margareth Ingrid Anggraeni ${ }^{1}$, Agus \\ Rizal A.H. Hamid 6 , Chaula Luthfia Sukasah ${ }^{1}$ \\ ${ }_{1}^{1}$ Plastic Reconstructive and Aesthetic Surgery Division, Department of Surgery, Cipto Mangunkusumo \\ National Hospital, Faculty of Medicine, Universitas Indonesia, Jakarta 10430, Indonesia \\ ${ }^{2}$ Research Center for Biomedical Engineering (RCBE), Universitas Indonesia, Kampus UI Depok, Depok \\ 16424, Indonesia \\ ${ }^{3}$ Department of Clinical Microbiology, Faculty of Medicine, Universitas Indonesia, Jl. Salemba Raya No.6, \\ Jakarta 10320, Indonesia \\ ${ }^{4}$ Department of Metallurgy and Material Engineering, Faculty of Engineering, Universitas Indonesia, \\ Kampus UI Depok, Depok 16424, Indonesia \\ ${ }^{5}$ Department of Mechanical Engineering, Faculty of Engineering, Universitas Indonesia, Kampus UI Depok, \\ Depok 16424, Indonesia \\ ${ }^{6}$ Department of Urology, Cipto Mangunkusumo National Hospital, Faculty of Medicine, Universitas \\ Indonesia, Jl. Salemba Raya No.6, Jakarta 10430, Indonesia
}

\begin{abstract}
The coronavirus disease 2019 (COVID-19) pandemic has caused an international shortage of nasopharyngeal flocked swabs, which are one of the main supplies for diagnostic testing. In response to this issue, our institution developed locally made nasopharyngeal swabs. This report aims to provide a clinical evaluation by conducting a sterility test, reverse transcription polymerase chain reaction (RT-PCR) compatibility test, and a user-based survey test of two batches of locally made flocked swabs. Sterility and compatibility tests were conducted at our microbiology laboratory. Participants with clinical suspicion of COVID-19 were scheduled for swab tests using Flocked Swab HS-19 and samples obtained were tested using the RT-PCR method. The cycle threshold (Ct) value of the samples was recorded. A user-based survey was conducted to evaluate the swab stick and flocked-fiber tip performance. The sterility test showed no evidence of bacterial growth on both blood agar and thioglycolate medium. RT-PCR compatibility test from Ct value of 33 samples of the first batch and 30 samples of the second batch was recorded with a mean Ct of $27.17 \pm 2.96$ and $23.99 \pm 2.18$, respectively. Six parameters of the swab stick (comfortability, smoothness, flexibility, durability, applicability, and breakpoint performance) showed satisfactory scores with an average of 4.14 out of 5.0 for the first batch and 4.16 for the second batch, while 4 parameters of the flocked-fiber tip (fiber adherence, thickness, symmetricity, and sample collection sufficiency) revealed acceptable scores with an average of 3.6 out of 5.0 for the first batch and 3.75 for the second batch. This study indicates that locally made flocked swabs are satisfactory and clinically applicable for testing and diagnosing COVID-19. Furthermore, mass production and distribution across the country are expected. The development of these swabs, which involved multidisciplinary teamwork and various industrial partners, portrayed a valuable lesson on how to cope with the pandemic through innovation.
\end{abstract}

Keywords: COVID-19; RNA extraction; Specimen collection; Swab 


\section{Introduction}

The coronavirus disease 2019 (COVID-19) was first reported in China in December 2019. Since then, the pandemic has exploded with more than 6.5 million cases globally and more than 380,000 deaths (National Institutes of Health, 2020). The World Health Organization (WHO) urged all nations to increase the testing for suspected cases in order to mitigate the spread of the virus (WHO, 2020). As a first-line method for diagnosing COVID19 , reverse transcription polymerase chain reaction (RT-PCR) molecular assays remain the gold standard test for the diagnosis of COVID-19 infection with isolated samples from respiratory tract specimens using nasopharyngeal flocked swabs (Ali et al., 2015; Ahn et al., 2020; WHO, 2020).

Indonesia remains in the escalating phase of the COVID-19 curve with 147,211 confirmed cases and 6,418 deaths (until August 20, 2020). The first case of COVID-19 in Indonesia was reported in March 2019 and 1.969.941 specimens have been tested (Kementerian Kesehatan Republik Indonesia, 2020). Moreover, with its 273 million population, Indonesia's testing ratio in a million stands at 1,703, which is low compared to other countries. The government aimed to increase the daily testing of 20,000 specimens, and currently, there are 110 laboratories across the country that are capable of rapid molecular testing using the RT-PCR method (Maharani, 2020; Berawi, 2020). However, this procedure will involve a significant amount of human resources and diagnostic testing supplies, including the flocked swabs. Due to the increased global demand, flocked swabs are in shortage and the price is skyrocketing (The Organization for Economic Co-operation and Development, 2020). To date, all of the flocked swabs available in the country are imported.

In response to this issue, technology and university-industry collaborations need to be employed (Hanid et al., 2019; Berawi et al., 2020). In conjunction with industrial partners, our institution designed and manufactured a locally made nasopharyngeal swab called "Dacron Swab HS 19," using food-grade resin material and flocked fiber. Series of tests for the mechanical properties have been conducted by the engineering team after developing the prototype. This study focuses on the clinical evaluation of the flocked swabs as the next step towards their mass production and distribution.

Sterility test, RT-PCR compatibility test, and user-based survey test, comprising the swab stick performance (comfortability, smoothness, flexibility, durability, applicability, and breakpoint performance) and flocked-fiber tip performance (fiber adherence, thickness, symmetricity, and sample collection sufficiency), were conducted. We expected that these locally made flocked swabs would be clinically applicable for testing and diagnosing COVID19 and mass producing and distributing them across the country.

\section{Methods}

This is a descriptive study reporting the results of the sterility test, RT-PCR compatibility test, and user-based survey. All data were obtained primarily. Data on the RT-PCR compatibility test was obtained from the samples taken using locally made flocked swabs at the clinical microbiology laboratory of Universitas Indonesia. Data on the user-based survey was obtained from multiple swab testing centers in Indonesia.

Two batches of the production of locally made flocked swabs were compared in terms of the RT-PCR compatibility and user-based survey. The second batch was produced after evaluating the result of the user-based survey of the first batch. We analyzed the data to identify improvements in the production of the batch and the overall clinical applicability of the locally made flocked swabs. 


\subsection{Design and Production}

Our team from the mechanical engineering department developed the design for the flocked swab and produced a small number of batch production. Two batches were produced. The second batch was an improvement of the first batch. The flocked swab stick consists of three parts: the head part is the rounded tip that consists of a layer of flocked fiber; the neck part is the middle part with the thinnest diameter to allow flexibility during insertion of the swab to the posterior nasopharynx; and the shaft has the thickest diameter with a breakpoint location that can be cut off after collecting the specimen to be put into the viral transport medium tube. The swab stick is made from polypropylene with the flocked fiber made from nylon. The flocking technique is conducted in an electrostatic field, which deposits the fiber in an ordered manner, perpendicular to the surface of the tip of the swab that has been previously coated with an adhesive. Finally, the flocked swab was then packaged and sterilized. The flocked swab design can be seen in Figure 1. The flocked swabs underwent mechanical tests and continued with the clinical evaluation, which consisted of a sterility test, RT-PCR compatibility test, and user-based survey test. After the distribution permit was issued by the Ministry of Health, the flocked swabs were mass-manufactured and distributed across the country.

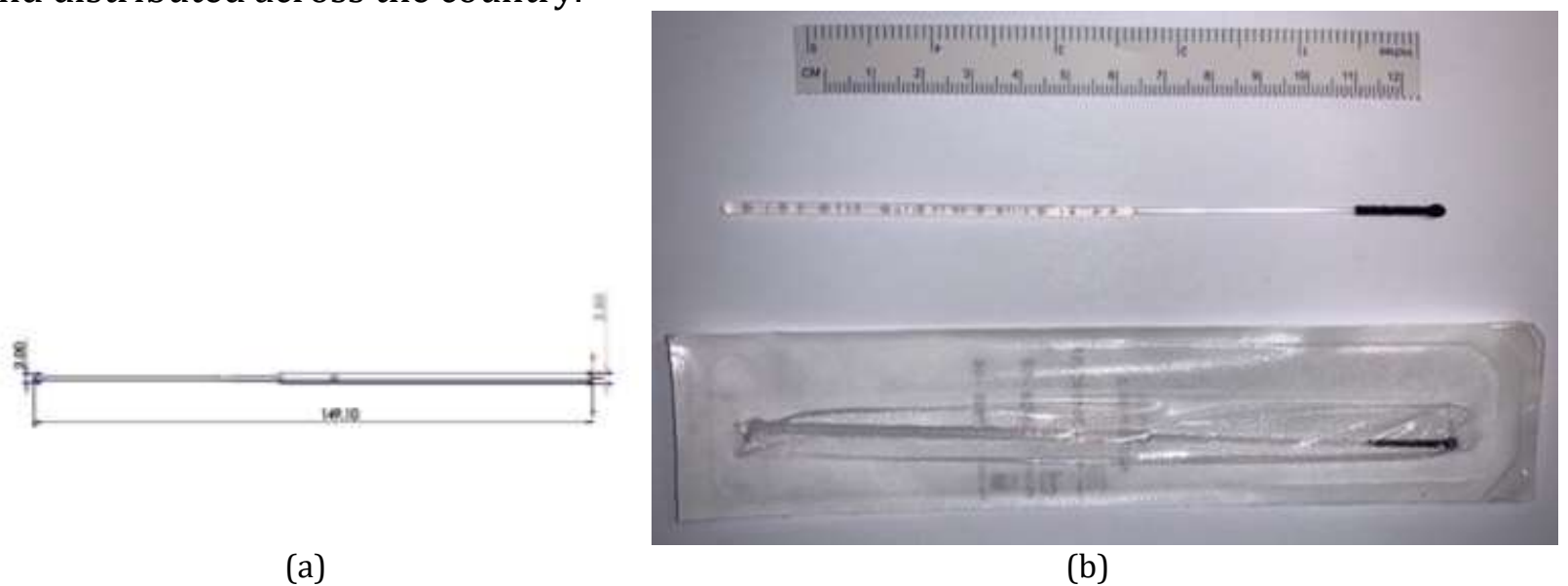

Figure 1 (a) Design and dimension of flocked swab HS 19; (b) Prototype of flocked swab HS 19 with the packaging

\subsection{Sterility Test}

Sterility test was conducted according to ISO-11133 guidelines and Indonesian's National Agency of Drug and Food Control guideline (ISO, 2014). The test was performed at a clinical microbiology laboratory, using blood agar medium and thioglycolate broth medium. The thioglycolate broth medium was prepared according to the WHO standards for sterility tests. Subsequently, both the medium was incubated at $30-35^{\circ} \mathrm{C}$ to support aerobes and anaerobes microorganism growth for 14 days. Experienced clinical microbiology specialist observed the cultures several times during and at the resolution of the incubation period for macroscopic evidence of microbial growth (Parveen et al., 2011; WHO, 2012).

\subsection{RT-PCR Compatibility}

Participants with clinical suspicion of COVID-19 were scheduled for swab tests. Participants were given a study information sheet and gave verbal informed consent. The swab tests were conducted at a clinical microbiology laboratory. Specimens were sampled by residents of clinical microbiology who underwent training on bio-safety/bio-security 
and nasopharyngeal swab sampling. The personnel were equipped with level 3 personal protective equipment (PPE), including coverall clothing, disposable head cap, N95 mask, goggles, face shield, double gloves, waterproof boots, and shoe covers. The sampling was done using the locally made flocked swab to the posterior nasopharynx. The swab stayed in the sampling area for 15-30 seconds and then gently rotated 3-5 times. Subsequently, the swab was transferred to a cryotube containing a viral transport medium with the flocked-fiber tip fully dispersed into the medium (Kojima et al., 2020).

The RNA extraction process was performed using a commercially available extraction kit (Daan Gene, China). The extracted RNA was tested by CFX96 Biorad or LC96 Roche machine and commercially available PCR kit for severe acute respiratory syndrome CoV-2 using the RT-PCR method. The cycle threshold (Ct) value of the samples was obtained. $\mathrm{Ct}$ value was documented for each internal control of the sample. Values less than 40 (for the sample) and 35 (for the internal control) were considered satisfactory (Holshue et al., 2020; Tom and Mina, 2020).

\subsection{User-Based Survey}

The users of the locally made flocked swab were given a study information sheet and gave verbal informed consent. The users were given a survey regarding the usability of the flocked swab. The survey was divided into three parts, with each comprising queries regarding the swab stick, the flocked-fiber tip, and the overall performance of the swab (Figure 2). The swab stick was evaluated for its comfortability, smoothness, flexibility, durability, applicability, and breakpoint performance. Questions regarding the flockedfiber tip assessed its fiber adherence, thickness, symmetricity, and specimen collection sufficiency (Holshue et al., 2020). General information of the participants, such as name, occupation, affiliation, and area were also recorded.

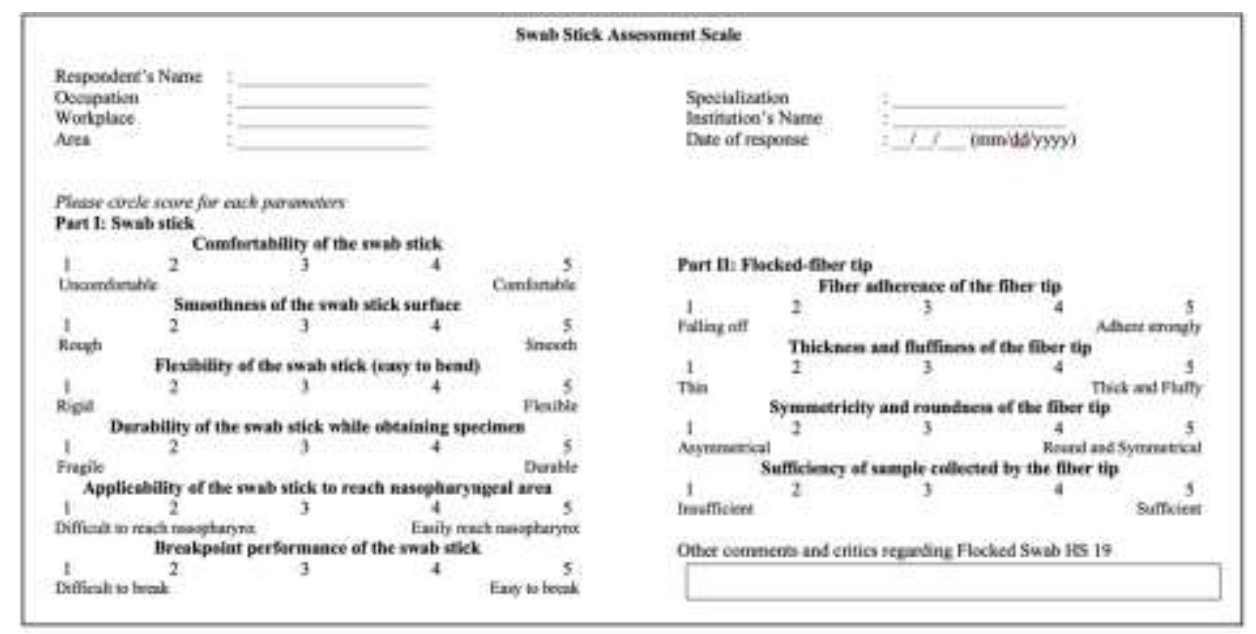

Figure 2 User-based survey consisted of swab stick performance (comfortability, smoothness, flexibility, durability, applicability, and breakpoint performance) and flocked-fiber tip performance (fiber adherence, thickness, symmetricity, and sample collection sufficiency)

\section{Results and Discussion}

\subsection{Sterility Test}

The sterility test from the clinical microbiology laboratory showed no evidence of bacterial growth on both blood agar and thioglycolate broth medium (Figure 3). 


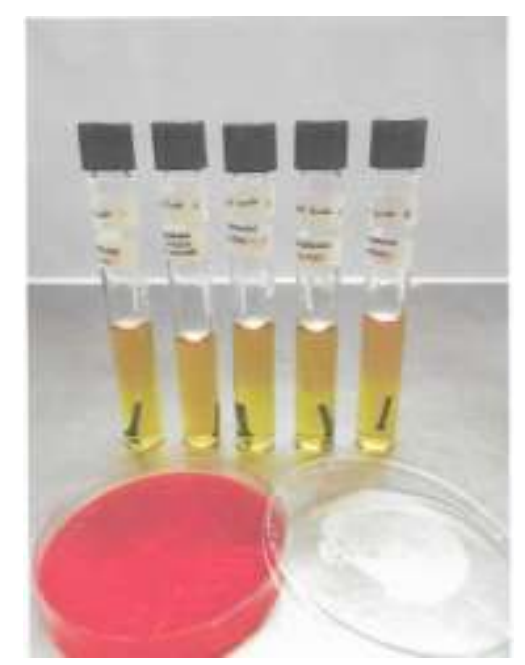

Figure 3 Sterility test showed no evidence of bacterial growth on both blood agar (petri dish) and thioglycolate broth medium (tube)

\subsection{PCR Compatibility}

Ct value of 33 samples from the first batch and 30 samples from the second batch internal control is presented in Figure 4. The mean \pm standard deviations $\mathrm{Ct}$ of the first and second batch were $27.17 \pm 2.96$ and $23.988 \pm 2.18$, respectively.

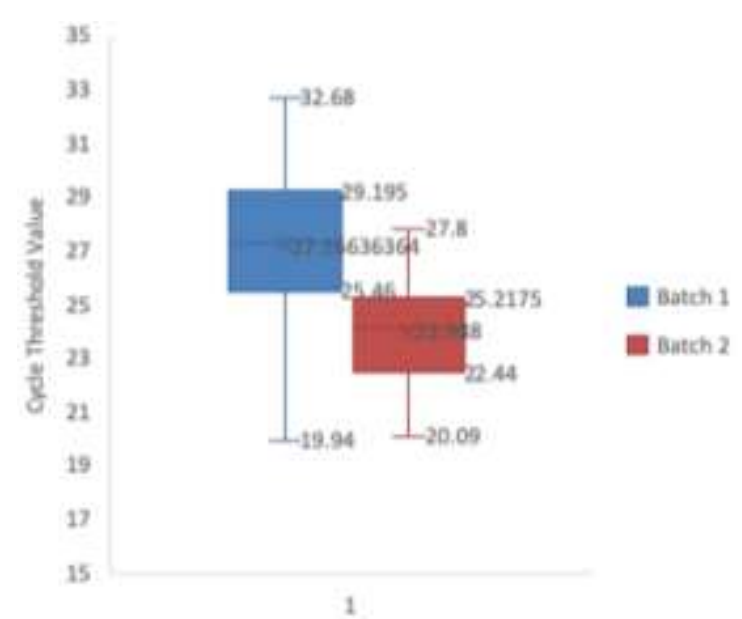

Figure 4 Internal control cycle threshold $(\mathrm{Ct})$ value is less than 35 for both batches. The results showed that the samples were adequate to detect COVID-19 RNA as a diagnostic tool

\subsection{User-Based Survey}

Questionnaires for the first batch were completed by 21 respondents through an online platform. The majority of the respondents (48\%) were laboratory analysts. Among all workplace settings, most of the respondents worked in hospital settings (71\%). Twelve of 21 respondents (57\%) were from the DKI Jakarta area. Twenty-one respondents completed the questionnaires for the second batch and most of them (48\%) were medical specialists working in hospital settings (52\%). Similarly, the majority of the respondents for the second batch were from DKI Jakarta (62\%). Other respondents' characteristics were summarized in Table 1.

The mean scores for the swab stick and flocked fiber parameters are presented in Figure 5 and Figure 6, respectively. For the first batch, as represented in Figures 5 and 6, the highest mean score for the swab stick parameter was 4.43 out of 5 for applicability, representing the swab stick performance to reach the nasopharyngeal area for specimen 
collection. The lowest score was for the smoothness of the swab stick (3.67 out of 5). Other commentaries regarding the swab stick comprised of difficulty to break the swab stick from two respondents, lack of durability according to one respondent, and notion to make depth indicator of the swab stick more prominent, which could easily be identified by users while using level 3 PPE. Overall, the mean score of the flocked fiber tip parameters was lower than the swab stick, with the highest score at 3.90 out of 5 for its symmetricity. The fiber adherence parameter was scored lowest at 3.10 out of 5 , as reflected in other commentaries consisting of 8 respondents commented about the fiber which, according to these respondents, is easily a fall off. Another input from the respondents for the flocked fiber was concerning the softness, shape, and thickness of the fiber.

There were improvements in the second batch in three of the swab stick parameters (comfortability, smoothness, and flexibility); however, there were decreases in the scores for durability (4.14 out of 5), applicability (4.38 out of 5), and breakpoint performance (4.1 out of 5). One of the respondents stated the swab was too flexible and two other respondents pointed out the lack of quality of the swab breakpoint. For the flocked fiber parameters, the second batch of the swab scored superiorly than the first swab with higher mean scores, except for the sample collection sufficiency (3.62 out of 5). Seven of 23 respondents highlighted the fall-off fiber, which remains an issue despite the improvement in fiber quantities. Other commentaries consisted of input to change the color of the fiber (preferably white) and make thinner flocked fibers. Overall, the second batch showed improvement compared to the first batch. The average scores of the first batch were 4.14 for the swab stick and 3.6 for the flocked fiber tip, while the second batch showed average scores of 4.16 for the swab stick and 3.75 for the flocked fiber tip.

Table 1 Respondents' Characteristic

\begin{tabular}{lcrrr}
\hline & \multicolumn{2}{c}{ Batch 1} & \multicolumn{2}{c}{ Batch 2} \\
Characteristic & \multicolumn{1}{c}{$(\mathrm{N}=21)$} & $(\mathrm{N}=21)$ \\
\cline { 2 - 5 } & $\mathrm{N}$ & $\%$ & $\mathrm{~N}$ & $\%$ \\
\hline Occupation & & & & \\
$\quad$ Laboratory Analyst & 10 & $48 \%$ & 7 & $33 \%$ \\
Medical Specialist/Consultant & 6 & $29 \%$ & 10 & $48 \%$ \\
$\quad$ Clinical Microbiology & 2 & $9.5 \%$ & 1 & $5 \%$ \\
$\quad$ Clinical Pathology & 4 & $19 \%$ & 6 & $29 \%$ \\
General Practitioner & 2 & $10 \%$ & 4 & $19 \%$ \\
Pharmacist & 1 & $5 \%$ & 0 & $0 \%$ \\
Head of Disease Control Division & 1 & $5 \%$ & 0 & $0 \%$ \\
Nutritionist & 1 & $5 \%$ & 0 & $0 \%$ \\
\hline Workplace & & & & \\
Public Health Office & 1 & $5 \%$ & 2 & $10 \%$ \\
Pharmacy Faculty & 1 & $5 \%$ & 0 & $0 \%$ \\
Primary Healthcare Provider & 3 & $14 \%$ & 3 & $14 \%$ \\
Laboratory & 1 & $5 \%$ & 5 & $24 \%$ \\
Hospital & 15 & $71 \%$ & 11 & $52 \%$ \\
\hline Area & & & & \\
Banten & 1 & $5 \%$ & 0 & $0 \%$ \\
Batam & 1 & $5 \%$ & 1 & $5 \%$ \\
DI Yogyakarta & 2 & $10 \%$ & 1 & $5 \%$ \\
DKI Jakarta & 12 & $57 \%$ & 13 & $62 \%$ \\
\hline East Java & 0 & $0 \%$ & 1 & $5 \%$ \\
West Kalimantan & 1 & $5 \%$ & 1 & $5 \%$ \\
South Sulawesi & 1 & $5 \%$ & 0 & $0 \%$ \\
Southeast Sulawesi & 2 & $10 \%$ & 2 & $10 \%$ \\
North Sulawesi & 1 & $5 \%$ & 0 & $0 \%$ \\
\hline
\end{tabular}




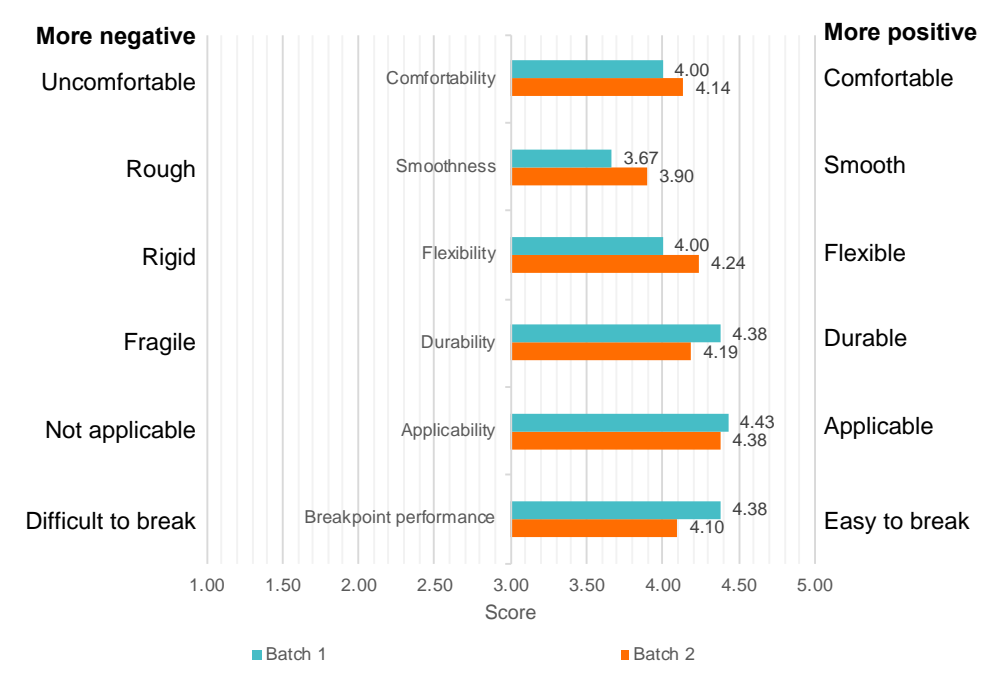

Figure 5 Swab stick assessment showed satisfactory scores and improvement in the second batch with an average of 4.14 of 5.0 for the first batch and 4.16 for the second batch

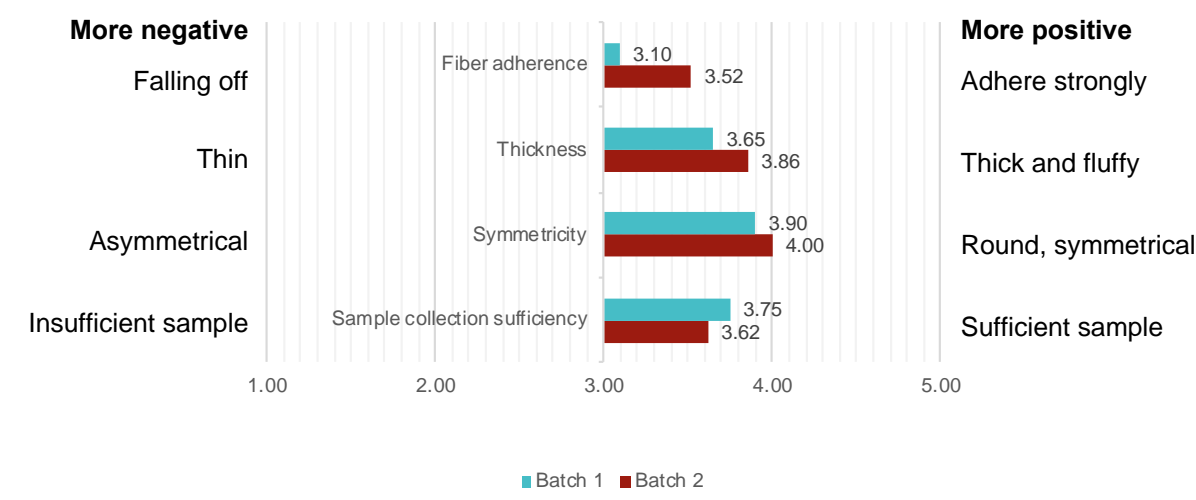

Figure 6 Flocked-fiber tip assessment showed acceptable scores and improvement of the second batch with an average of 3.6 out of 5.0 for the first batch and 3.75 for the second batch

Previous studies have shown innovations on flocked swabs, two of these innovations are silicone swab by Zhou et al and 3D printing swab by Callahan et al. (Callahan et al., 2020; Zhou et al., 2020). To the best of our knowledge, "Dacron swab HS 19" is the first locally made flocked swab in Indonesia, representing the first research and innovation of flocked swab in this country. This paper reports good sterility test results and RT-PCR compatibility tests resulting in acceptable $\mathrm{Ct}$ of internal control value of this flocked swab for both the production batches. The usability test revealed some improvements that still need to be worked upon for Flocked Swab HS 19. One of the highlighted issues is the inadequate fiber adherence of the flocked-fiber tip causing a fall-off of the fiber. Referring to the production process, this issue might be the result of the flocking process in which the amount of fiber delivered was more than the surface of the adhesive at the tip of the swab stick, so the "falloff" fiber was the residue of unflocked fibers. However, this issue did not affect the outcome of the swab test results, indicated by the sufficient sample obtained based on the survey, as well as the result of Ct test, which was still acceptable. Improvement of the flocked swab fiber adherence in the second batch swabs was recorded objectively by the improvement of CT value and subjectively by increased user-based survey parameter score. The limitation of this study includes the lack of a control group or comparison between the locally made flocked swabs and other commercial flocked swabs. Further improvement and refinement are part of a ceaseless process in product development and these tests paved 
the way for Flocked Swab HS 19 to be mass manufactured and widely distributed after obtaining a distribution permit.

Our industrial partners are vital to this study, making this project possible. Currently, the production capacity of the flocked swab is 50,000 units per week. On June 29, Indonesia's test ratio in a million population is 1,703. According to Our World in Data's COVID-19 testing dataset among the countries worldwide, Bahrain and Luxembourg performed most tests in a million population at 315,304 and 285,000, respectively. While in ASEAN, Singapore ranked first with 70,833 test ratio in a million population (Roser et al., 2020). This data emphasizes the significant inadequacy of COVID-19 testing in Indonesia relative to its population in comparison with other countries. With over 273 million population, Indonesia needs to increase its test ratio in a million population in order to effectively mitigate this pandemic. Aiming for a 50,000 test ratio in a million population for Indonesia suggests that roughly another 13 million tests are required and an even higher number of collecting samples is necessary because multiple sampling might be needed for some individuals. To meet this requirement, increasing the production capacity of the flocked swab is critical. This product development involved multiple departments with different scientific fields working together for a common purpose. While this pandemic is predicted to last up to 2 years (Moore et al., 2020), constant improvement and development, including the industrial partners' continuous involvement for flocked swab production, is very essential.

\section{Conclusions}

To mitigate the spread of the virus, an increase in the testing of COVID-19 is needed for this vastly populated country. However, the pandemic has caused an international shortage of nasopharyngeal flocked swabs. As a result, this has led to the innovation and development of locally made flocked swabs, which involves multidisciplinary teamwork and various industrial partners. This study shows that locally made flocked swabs are satisfactory and clinically applicable for testing and diagnosing COVID-19. Further improvement and refinement are part of a learning process in product development and this report encourages further increase in mass-production and distribution capacity of flocked swabs in response to the pandemic. Future studies comparing locally made and imported flocked swabs are warranted.

\section{Acknowledgements}

Our industrial partners involved in this project: PT Chandra Asri Petrochemical Tbk., Dynapack Asia Pte Ltd, PT Ingress Malindo Venture, PT Langgeng Jaya Fiberindo, PT Sri Tita Medika, PT Indachi Prima, and PT Toyota Motor Manufacturing Indonesia.

\section{References}

Ahn, D.G., Shin, H.J., Kim, M.H., Lee, S., Kim, H.S., Myoung, J., Kim, B.T., Kim, S.J., 2020. Current Status of Epidemiology, Diagnosis, Therapeutics, and Vaccines for Novel Coronavirus Disease 2019 (COVID-19). Journal of Microbiology and Biotechnology, Volume 30(3), pp. 313-324

Ali, M., Han, S., Gunst, C.J., Lim, S., Luinstra, K., Smieja, M., 2015. Throat and Nasal Swabs for Molecular Detection of Respiratory Viruses in Acute Pharyngitis. Virology Journal, Volume 12, p. 178-182

Berawi, M.A., 2020. Empowering Healthcare, Economic, and Social Resilience during Global Pandemic Covid-19. International Journal of Technology, Volume 11(3), p. 436-439 
Berawi, M.A., Suwartha, N., Kusrini, E., Yuwono, A.H., Harwahyu, R., Setiawan, E.A., Yatmo, Y.A., Atmodiwirjo, P., Zagloel, Y.M., Suryanegara, M., Putra, N., Budiyanto, M.A., Whulanza, Y., 2020. Tackling the COVID-19 Pandemic: Managing the Cause, Spread, and Impact. International Journal of Technology, Volume 11(2), pp. 209-214

Callahan, C.J., Lee, R., Zulauf, K.E., Tamburello, L., Smith, K.P., Previtera, J., Cheng, A., Green, A., Abdul Azim, A., Yano, A., Doraiswami, N., Kirby, J.E., Arnaout, R.A., 2020. Open Development and Clinical Validation of Multiple 3D-Printed Nasopharyngeal Collection Swabs: Rapid Resolution of a Critical COVID-19 Testing Bottleneck. Journal of Clinical Microbiology, Volume 58(8), pp. 1-10

Hanid, M., Mohamed, O., Othman, M., Danuri, M.S.M., Ye, K.M., Berawi, M.A., 2019. Critical Success Factors (CSFs) in University-Industry Collaboration (UIC) Projects in Research Universities. International Journal of Technology, Volume 10(4), pp. 667-676

Holshue, M.L., DeBolt, C., Lindquist, S., Lofy, K.H., Wiesman, J., Bruce, H., Spitters, C., Ericson, K., Wilkerson, S., Tural, A., Diaz, G., Cohn, A., Fox, L., Patel, A., Gerber, S.I., Kim, L., Tong, S., Lu, X., Lindstrom, S., Pallansch, M.A., Weldon, W.C., Biggs, H.M., Uyeki, T.M., Pillai, S.K., 2020. First Case of 2019 Novel Coronavirus in the United States. The New England Journal of Medicine, Volume 382(10), pp. 929-936

International Organization for Standardization (ISO), 2014. ISO 11133:2014(en). Microbiology of Food, Animal Feed and Water - Preparation, Production, Storage and Performance Testing of Culture Media. Available Online at https://www.iso.org/standard/53610.html, Accessed on June 26, 2020

Kementerian Kesehatan Republik Indonesia, 2020. Situasi Infeksi Emerging: Info COVID-19 (Current COVID-19 Situation in Indonesia). Available Online at https://covid19.kemkes.go.id/category/situasi-infeksi-emerging/info-coronavirus/\#.XuepSi-7qfA, Accessed on August 20, 2020

Kojima, N., Turner, F., Slepnev, V., Bacelar, A., Deming, L., Kodeboyina, S., Klausner, J.D., 2020. Self-Collected Oral Fluid and Nasal Swabs Demonstrate Comparable Sensitivity to Clinician Collected Nasopharyngeal Swabs for Covid-19 Detection. medRxiv (The Preprint Server for Health Sciences), pp. 1-13

Maharani, T., 2020. Targetkan 20000 tes COVID-19 per hari pemerintah pastikan jumlah laboratorium cukup (Aiming for 20.000 COVID-19 Tests Daily, Indonesian's Government Assure Laboratories Adequacy). Available Online at https://nasional.kompas.com/read/2020/06/05/17401691/targetkan-20000-tescovid-19-per-hari-pemerintah-pastikan-jumlah-lab-cukup, Accessed on June 10, 2020

Moore, K.A., Lipsitch, M., Barry, J.M., Osterholm, M.T., 2020. COVID-19: The CIDRAP Viewpoint. The Center for Infectious Disease Research and Policy. Available Online at https://www.cidrap.umn.edu/sites/default/files/public/downloads/cidrap-covid19viewpoint-part1_0.pdf, Accessed on June 26, 2020

National Institutes of Health, 2020. COVID-19 Treatment Guidelines Panel. Coronavirus Disease 2019 (COVID-19) Treatment Guidelines. Available Online at https://www.covid19treatmentguidelines.nih.gov/, Accessed on June 10, 2020

Parveen, S., Kaur, S., David, S.A.W., Kenney, J.L., McCormick, W.M., Gupta, R.K., 2011. Evaluation of Growth Based Rapid Microbiological Methods for Sterility Testing of Vaccines and Other Biological Products. Vaccine, Volume 29(45), pp. 8012-8023

Roser, M., Ritchie, H., Ortiz-Ospina, E., Hasell, J., 2020. Coronavirus Pandemic (COVID-19). Available Online at https://ourworldindata.org/coronavirus, Accessed on June 26, 2020

The Organization for Economic Co-operation and Development, 2020. Testing for COVID10: A Way to Lift Confinement Restrictions. Available Online at https://read.oecd- 
ilibrary.org/view/?ref=129_129658-162d7lr66u\&title=Testing-for-COVID-19-A-wayto-lift-confinement-restrictions, Accessed on June 12, 2020

Tom, M.R., Mina, M.J., 2020. To Interpret the SARS-CoV-2 Test, Consider the Cycle Threshold Value. Clinical Infectious Diseases, pp. 1-8

World Health Organization, 2020. Clinical Management of COVID-19: Interim Guidance, 27 May 2020. Available Online at https://apps.who.int/iris/handle/10665/332196, Accessed on June 26, 2020

World Health Organization, 2020. Laboratory Testing Strategy Recommendations for COVID-19: Interim Guidance, 21 March 2020. Available Online at https://apps.who.int/iris/handle/10665/331509, Accessed on June 26, 2020

World Health Organization, 2012. Test for Sterility. Available Online at https://www.who.int/medicines/publications/pharmacopoeia/TestForSterilityRevGenMethod_QAS11-413FINALMarch2012.pdf, Accessed on June 26, 2020

Zhou, J., Bai, Z., Liu, X., Guo, Y., Jiang, N., Li, X., Zhang, X., Li, Z., Li, Y., Ma, Z., Zhao, J., 2020. Flocked Swab might be One Main Reason Causing the High False-Negative Rate in COVID-19 Screening----The Advantages of a Novel Silicone Swab. bioRxiv (The Preprint Server for Biology), pp. 1-15 